\section{Spastic Quadriplegia due to Electric Shock}

\author{
S. C. SO, M. L. K. LEE
}

British Medical fournal, 1973, 2, 590

We report here a case of non-progressive, permanent spastic quadriplegia and noticeable wasting of the small muscles of the hands developing early after electric shock-a sequence of events which has not, so far as we know, been previously recorded.

\section{Case Report}

A 49-year-old Chinese factory worker sustained a $220-\mathrm{V}$ alternating current electric shock when his right hand touched a live wire. In falling he knocked over a container of water which soaked him completely. He briefly lost consciousness, but he was neither apnoeic nor cyanosed. When he recovered consciousness he could not move his limbs and he complained of generalized paraesthesia, described as tingling and pin-pricking in character, mostly in the legs. There was no disturbance of the special senses.

On admission to hospital the patient was lethargic but able to reply to simple questions. He had a flaccid quadriplegia, the tendon reflexes were greatly diminished, the abdominal reflexes absent, and the plantar responses equivocal. A generalized hyperalgesia made assessment of sensory function impossible. There was a small second degree burn on the right hand, but otherwise nothing abnormal was found on examination. Twelve hours after admission he was alert and gave an accurate account of his accident. He could move both arms. Muscle tone and tendon reflexes had returned but power in all muscles was impaired. Paraesthesia and hyperalgesia were no longer present in the arms, neck, and head but persisted in the legs, in which a marked degree of spasticity was increased on attempted passive movement and affected equally both the flexor and extensor muscles. Knee and ankle jerks were brisk, bilateral sustained ankle clonus was elicited, and the plantar responses were extensor. Examination of the sensory system showed impairment of function of the posterior columns and spinothalamic tracts from the neck down. The only abnormality detected on lumbar puncture was a protein content in the cerebrospinal fluid of $105 \mathrm{mg} / 100 \mathrm{ml}$. Myelography showed nothing abnormal.

The paraesthesia and hyperalgesia in the lower limbs gradually disappeared after 48 hours, but were succeeded by attacks of lightning pains, which persisted over a period of 24 hours. On the third day urinary retention oocurred and there was loss of tone in the anal sphincter. By the fifth day after the accident sensory function was normal but the signs of pyramidal tract involvement were unchanged. The muscle tone of the arms was increased and the tendon reflexes had become brisk. The patient could move his arms weakly but he was completely paralysed from the waist down. After two weeks wasting of the muscles of both hands, more severe on the right, was noted. There was no fasciculation. The wasting progressed and reached its maximum by the end of the third week.

University of Hong Kong, Queen Mary Hospital, Hong Kong

S. C. SO, M.B., B.S., Lecturer in Surgery

M. L. K. LEE, M.B., M.R.C.P., Honorary Lecturer in Medicine
When seen recently, two years after his accident, the patient had severe spastic quadriplegia with complete immobility of the lower limbs. His upper limbs, though spastic, still had substantial power, especially proximally, but distally strength was grossly diminished, particularly on the right side. His hands were clawed and wasted. Sensations were intact except for a mild impairment of vibration sense and proprioception in the limbs. His jaw jerk and abdominal reflexes were absent but all the other tendon reflexes were grossly exaggerated with easily elicitable knee and ankle clonus. Electrical studies with a concentric needle-electrode inserted into the right first dorsal interosseus muscle showed spontaneous fibrillation potentials in profusion. A few poorly-formed, low-voltage motor unit action potentials appeared on volition, with a grossly reduced interference pattern. Terminal latency of the ulnar nerve at the wrist was recorded at $3.0 \mathrm{~m} / \mathrm{sec}$ and motor conduction velocity along the ulnar nerve in the forearm was normal at $68 \mathrm{~m} / \mathrm{sec}$. Sensory nerve action potentials of $20 \mu \mathrm{V}$ at a normal latency were obtainable over the median and ulnar nerves at the wrist by applying stimuli to ring electrodes wound around the appropriate fingers.

\section{Comment}

The extent of electrical injury depends on the voltage and the route of passage through the body (Silversides, 1964). In this patient the decrease in surface resistance due to moisture probably resulted in a large amount of current passing through the right hand. Both pyramidal tracts were affected about 12 hours after injury, and the lesion progressed rapidly to involve the upper limbs as well four days later.

Morrison et al. (1930) showed that after electric shock there is chromatolysis of the ganglion cells of the brain, wide dilatation of the perivascular spaces, and vascular lesions in the form of petechial haemorrhages affecting mainly the intracerebral capillaries. Heidrich et al. (1965) observed similar changes in their animal experiments. The pyramidal tract lesions in our patient were permanent, and presumably the upper motor neurones or their descending fibres must have been damaged at the time of injury. That the damage from the electric shock can be so highly selective and localized is amazing. Permanent damage to the pyramidal tract from electric shock has been reported by Planques and Paquiet (1958), but in their patients the effects were unilateral.

The other peculiar feature of our case was the symmetrical wasting of the small muscles of the hand. Electromyography done two years later confirmed that they were denervated. Pugliese (1966) reported a typical case of amyotrophic lateral sclerosis resulting from electrical injury, and Panse (1967) also showed that slow progressive spinal muscular atrophy can occur as a sequel. Haynal and Regli (1964) tried to establish a causal relation between electric shock and the development of amyotrophic lateral sclerosis some five to 10 years later. However, the muscle wasting in our patient, unlike motor-neurone disease, was apparent soon after the accident and was unchanged two years later.

\section{References}

Haynal, A., and Regli, F. (1964). Confina Neurologica, 21, 189. Heidrich, R., Leder, H., and Palm, K. (1965). Deutsche Zeitschrift für Nervenheilkunde, 187, 317.

Morrison, L. R., Weeks, A., and Cobb, S. (1930). Journal of Industrial Hygiene and Toxicology, 12, 324.

Panse, F. (1967). Therapiewoche, 17, 837.

Planques, J., and Paquiet, J. (1958). Gazette des Hôpitaux Civils et Militaires, 130,621 .

Pugliese, L. (1966). Rassegna di Studi Psichiatrici, 41, 402.

Silversides, J. (1964). Canadian Medical Association fournal, 91, 195. 